\title{
INCRUSTAÇÃO FERRUGINOSA DE NEURONIOS NOS INFARTOS CEREBRAIS
}

\author{
Aristides Cheto de Quetroz*
}

A incrustação ferruginosa neuronal é caracterizada pela deposição de granulações basofílicas densamente distribuídas pelo citoplasma e prolongamentos celulares, sendo descrita como ocorrendo em áreas de infarto no tecido nervoso ${ }^{2},{ }^{10}$. Nestas granulaçōes tem sido demonstrada, de maneira ainda discutivel, a existência de ferro, cálcio e outros minerais ${ }^{3,6}$. Apesar de ter sido descrita há muito tempo, vários pontos permanecem sem maiores esclarecimentos, tais como a sua distribuição nas lesões necróticas do sistema nervoso central, a origem dos minerais que existem nas células lesadas bem como os mecanismos relacionados ao seu aparecimento.

O presente trabalho foi realizado no sentido de verificar a distribuição desta lesão neuronal nos infartos cerebrais, na tentativa de correlacionar com possiveis fatores determinantes, bem como verificar a possivel origem dos elementos químicos, particularmente ferro e cálcio.

\section{MATERIAL E METODOS}

Foram estudados 87 casos de infartos cerebrais em individuos autopsiados, falecidos em decorrência de várias doenças, sendo mais frequentes as cardiopatias de diversas etiologias. Todos os casos foram submetidos a autópsias completas com exame macro e microscópico sistemático de todos os órgãos. Para o estudo do sistema nervoso central, os encéfalos foram examinados 20 dias após fixação em formol a $10 \%$, em suspensão. Os blocos colhidos para exame histológico foram incluídos em parafina e as secçōes, cortadas com espessura de $5 \mu \mathrm{m}$, foram coradas pela hematoxilina e eosina, pelo P.A.S. pelo método de Von Kossa para pesquisa de cálcio e pelo azul da Prussia para pesquisa de ferro.

\section{RESULTADOS}

A lesão neuronal (incrustação ferruginosa) foi encontrada em 40,3\% dos casos de infartos cerebrais examinados. As células incrustadas apresentavam estrutura geral de neurônios com o corpo celular grande e triangular, mostrando granulaçōes basofílicas quando coradas pela hematoxilina e eosina. As granulaçōes estavam densamente distribuidas no citoplasma e prolongamentos das células, apresentando menor densidade na região central correspondente ao núcleo (Figs. 1 e 2).

Serviço de Anatomia Patológica do Hospital Professor Edgar Santos, Salvador - Bahia: * Professor Assistente do Departamento de Anatomia Patológica e Medicina Legal (Setor Anatomia Patológica) da Faculdade de Medicina da Universidade Federal da Bahia. 
Esta alteração foi encontrada tanto nos infartos de núcleos de base como nos da cortex cerebral, sendo duas vezes mais frequente nesta última localização (Tabela 1). A lesão foi encontrada independente da idade do infarto, sendo mais frequente nos infartos antigos. Em 10 casos ficou demonstrada a presença de granulações basofilicas dispersas pela área de necrose nos infartos recentes e antigos (Fig. 3). A lesão neuronal deu reação fortemente positiva quando se pesquisou a existência de cálcio com o método de Von Kossa (Fig. 4). A pesquisa de ferro, com o método do azul da Prussia foi também positiva, porém com reação de menor intensidade. A análise das granulações extra-celulares mostrou reação positiva para cálcio e fracamente positiva para ferro. A coloração pelo P.A.S. foi positiva apenas nas granulações extra-celulares.

O gráfico 1 mostra a distribuição da lesão neuronal de acordo com a faixa etária. Chama atenção a maior incidência em individuos de idade mais avançada. Com referência ao sexo houve predileção para o sexo masculino na proporçâo de 2:1. Não houve correlação com qualquer tipo particular de doença básica apresentada pelos pacientes. Em $17 \%$ dos casos foram encontrados graus variáveis de falcemização de hemácias, sendo que o caso mais proeminente foi aquele em que se encontrou em maior intensidade a lesão neuronal (Fig. 1). Não houve qualquer relação entre a lesão neuronal e a presença de hemossiderina livre ou fagocitada por células histiocitárias.

Local dos infartos N. ${ }^{\circ}$ de casos examinados N. ${ }^{\circ}$ de casos positivos

Núcleos da base

Cortex cerebral
33

61
$7(21,2 \%)$

$27(44,3 \%)$

Tabela 1 - Frequência da incrustacão ferruginosa de neurônios nos infartos cerebrais de acordo com a localização anatômica.

\section{COMENTARIOS}

O presente estudo mostra que a lesão que vem sendo rotulada como incrustação ferruginosa de neurônios è mais comum em indivíduos idosos e tem nitida predileção para as lesões necróticas da córtex cerebral. Apesar de ser referida como lesão de ocorrência muito comum ${ }^{6}$, ela foi detectada aqui em apenas $40,3 \%$ do material estudado. O estudo histoquímico mostrou a presença de ferro e cálcio nos grânulos basofílicos intracelulares, sendo que o cálcio pareceu estar presente em maior quantidade tendo em vista a maior intensidade da reação tintorial. No que diz respeito à pesquisa destes minerais na lesão, alguns trabalhos ${ }^{2}, 3$ mostram resultados contraditórios quanto à existência de cálcio, ferro ou dos dois. Mais recentemente ficou demonstrada a existência não só de cálcio e ferro mas também de traços de zinco, cobre e cádmio ${ }^{6}$, o que levou o autor a sugerir o termo "mineralização de neurônios" como o mais apropriado. 
O mecanismo que determina este processo de mineralização de neurônios permanece ainda desconhecido. É possivel que esta lesão se faça a partir dos minerais existentes no próprio tecido nervoso. Sabe-se que estes elementos existem em quantidade variável neste tecido, sendo maior a concentração ao nível dos núcleos da base 1,5, 7. Esta hipótese fica fortalecida com a demonstração de granulações com reação positiva para ferro e cálcio nas lesões necróticas do tecido nervoso. O aumento da solubilidade destes minerais que ocorre nas áreas de necrose ${ }^{1}$, facilitaria a penetração rápida destes elementos no citoplasma do neurônio, justificando, inclusive, o aparecimento desta alteração nos infartos recentes. Existe, entretanto, um ponto contraditório que é o encontro mais comum desta lesão neuronal nas áreas corticais em relação aos núcleos da base, quando nestes últimos a presença de ferro e cálcio é normalmente maior ${ }^{\text {t }} 9$.

A hipótese de que esta incrustação resulte de distúrbio do metabolismo destes minerais é menos provável, pois nas doenças que decorrem com distúrbios do metabolismo do cálcio e ferro, a deposição destes elementos no sistema nervoso é feita principalmente na parede de vasos e raramente no interior de células 8,11 .

A associação desta lesão com falcemização de hemácias demonstrada em $17 \%$ dos casos, é um dado que merece mais investigação, principalmente porque já foi observada anteriormente e considerada entre os vários fatores associados à deposição de cálcio e ferro nos núcleos da base ${ }^{4}$.

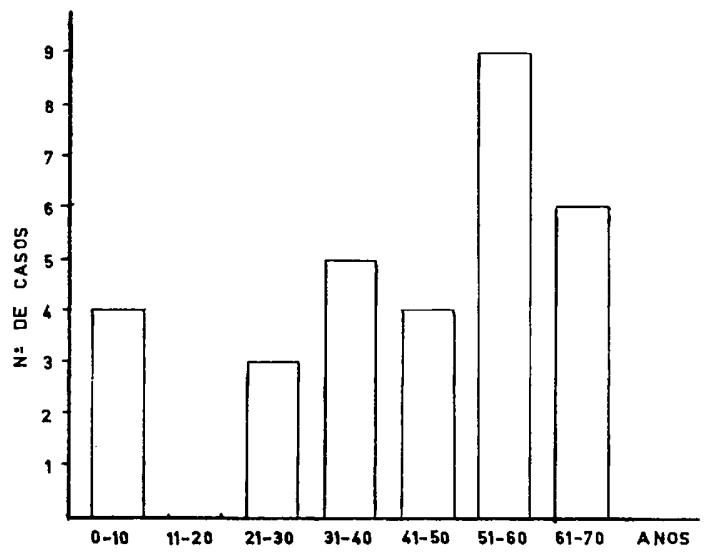

Gráfico 1 - Distribuicão da incrustação ferruginosa de neurônios nos infartos cerebrais de acordo com o grupo etário. 


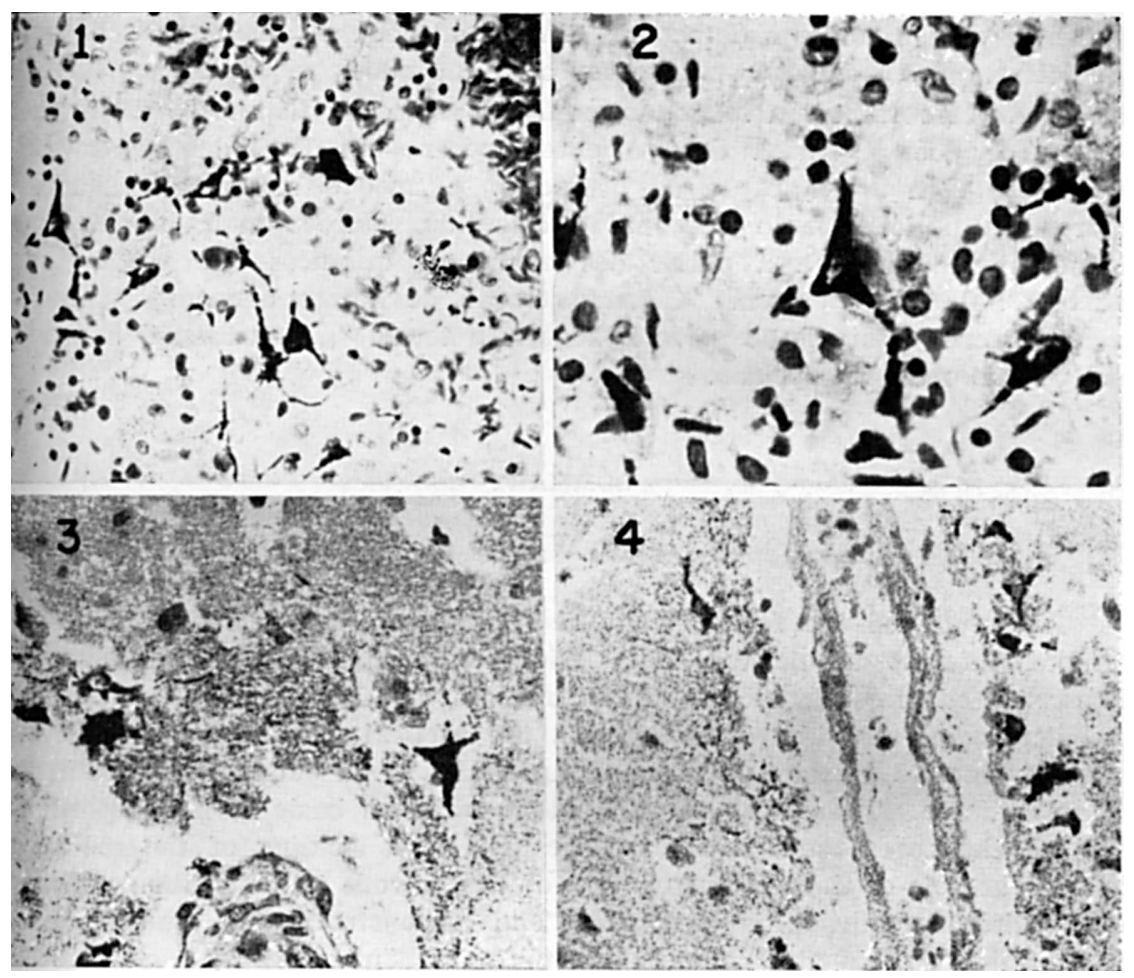

Fig. 1 - Seção de uma área de infarto antigo da cortex cerebral com neurônios mostrando granulacões basofilicas distribuidas pelo corpo e prolongamentos celulares. Observar a presença de hemácias falcemizadas (H.E. X 200).

Fig. 2 - Detalhe da figura anterior mostrando a menor densidade das granulações na porção central da célula, correspondendo à posição do núcleo (H.E. X 400).

F'ig. 3 - Area de infarto recente com vários neurônios com incrustação. Observar a presença de granulos basofilicos distribufdos pelo espaço extra-celular (H.E. X 200).

Fig. 4 - Secção corada pelo método de Von Kossa para a pesquisa de cálcio. Observar a positividade da reação nas granulaçóes intra e extra-celulares ( $X$ 200).

\section{RESUMO}

$\mathrm{Na}$ análise de 87 infartos cerebrais estudados em material de autópsia, ficou demonstrada a existência da lesão neuronal conhecida como incrustação ferruginosa de neurônios em $40,3 \%$ dos casos. Nesta lesão ficou evidenciada 
a presença de cálcio e ferro no citoplasma e prolongamentos celulares. Estes elementos foram também detectados em granulações extracelulares nas áreas necróticas. O encontro da lesão neuronal foi mais frequente nas necroses da córtex cerebral e em indivíduos mais idosos. Não houve correlação com o tipo de doença básica dos pacientes, porém em $17 \%$ dos casos havia associação com falcemização de hemácias. O mecanismo que determina o aparecimento desta lesão neuronal é discutido. Parece mais provável que a incrustação se faça a partir dos elementos químicos que rormalmente existem no tecido nervoso. A demonstração de outros elementos químicos, além do ferro, nesta lesão permite sugerir o termo "mineralização de neurônios" como mais apropriado.

\section{SUMMARY}

\section{Ferruginated neurons in the cerebral infarcts}

The study of the ferruginated neurons in the analysis of 87 cases of cerebral infarcts is reported. The lesion found in $40,3 \%$ of the cases was demonstrared to contain iron and calcium. It was found to be more frequent in older patients and predominantly in the cortical necrotic areas. The minerals were also detected in basophilic granules found outside the cells in the necrotic tissue. There was no correlation with the basic disease, althoug in $17 \%$ of the cases there was an association with sickling of the red blood cells. The role of the mineral content of the nervous tissue in the pathogenesis of the incrustation is discussed. The demonstration of other minerals besides the iron in the cells makes the term "mineralization of neurons" more acceptable.

\section{REFERENCIAS}

1. ALEXANDER, L. \& MYERSON, A. - The mineral content of various cerebral lesions as demonstrated by microincineration method. Am. J. Path. 13:405, 1937.

2. BLACKWOOD, W.; MCMENEMEY, W. H.; MEYER, A.; NORMAN, R. M. \& RUSSEL, D. S. - Ferrugination or iron incrustation of nerve cells. In Greenfield's Neuropathology. Williams \& Wilkins Co., Baltimore, 1967, pg. 36.

3. FANO, C. DA \& PERDRAU, J. R. - Calcification in the rabbit's brain. J. Path. Bact. 29:195, 1926.

4. ICHINOSE, H.; HARKIN, J. C. \& LITTLE, W. P. - Massive calcification of basal ganglia. Bull. Tulane Univ. Med. Faculty 26:91, 1967.

5. KOEPPEN, A. H. W. \& BARRON, K. D. - Superficial siderosis of the central nervous system: a histological, histochemical and chemical study. J. Neuropath. Exp. Neurol. 30:448, 1971.

6. LEESTMA, J. E. \& MARTIN, E. - An electron probe and histochemical study of the ferruginated neuron. Arch. Path. 86:597, 1968.

7. MAFFEI, W. E. - Organização e estrutura geral do sistema motor extra-piramidal. In Fundamentos da Medicina. Editado pelo Fundo Procienx, São Paulo, 1967, pg. 558.

8. NEUMANN, M. A. - Hemochromatotic pigmentation of the central nervous system: a clinicopathological study. Arch. Neurol. Psychiat. (Chicago) 76: $355,1956$. 
9. NEUMANN, M. A. - Iron and calcium dysmetabolism in the brain with special predilection for globus palidus and cerebellum. J. Neuropath. Exp. Neurol. $22: 148,163,1963$.

10. SEITELBERGER, F. - Pigmentary disorders. In Jeff Minckler - Pathology of the Nervous System, Vol. 2. MacGraw-Hill Book Co., New York, 1971, pg. 1332 .

11. STRASSMAN, G. - Hemosiderin and tissue iron in the brain: its relationship, occurrence and importance. A study of ninety three human brains. J. Neuropath. Exp. Neurol. 4:393, 1945.

Serviço de Anatomia Patológica - Hospital Prof. Edgard Santos - 40000 Salvador, BA - Brasil. 